\title{
Thoreauea guerrerensis (Apocynaceae, Apocynoideae), una Nueva Especie de Guerrero, México
}

\author{
Nelly Diego Pérez y Lucio Lozada Pérez \\ Facultad de Ciencias, UNAM, Apartado Postal 70-282, México D.F. 04510. México. \\ luciolozada@holmail.com
}

Restura. Se propone una nueva especie de Thoreauea J. K. Williams. Esta especie difiere de Thoreauea paneroi J. K. Williams por tener una corona corolina l0-lobulada en el ápice y estambres lan largos como la corona. La especie que aquí se describe tiene como hábitat los bosques de Pinus I.. Quercus L.. Abies Miller y bosque mesófilo de montaña que se localizan en la parte más alta de la Sierra de Guerrero. Se describen por primera vez los frutos y las semillas para el género.

Abstract. A new species of Thoreauea J. K. Williams is proposed. This species differs from Thoreanea paneroi J. K. Williams in its corolline crown I0lobulate at the apex and stamens as long as the crown. The species described in this paper was found in habitats of forests of Pinus L., Ouercus I... and Abies Miller and in montane rain forest found in the highest region of the Sierra of Guerrero. The fruits and seeds are described for the first time for this genus.

Key words: Apocynaceae, Apocynoideae, Guerrero, Mexico, Thoreanea.

El estudio de las Apocynaceae (Apocynoideae) en la Sierra de Guerrero a lo largo de varios años permitió reunir una colección de especímenes cuyas características corresponden al género Thoreauea J. K. Williams, recientemente descrito por Williams (2002a), con una sola especie Thoreanea paneroi J. K. Williams. Para determinar si el material de Guerrero correspondía a esta especie fue visitada la localidad lipo del género para colectar especímenes vivos de dicha especie. las flores de estos especímenes se caracterizan por presentar en la garganta una corona corolina profundamente 5-lobulada y el ápice de las anteras apenas alcanza la base de la corona, o sea de la garganta: en cambio las flores de los especímenes de Guerrero poseen una corona corolina ligeramente 10-lobulada y las anteras alcanzan el ápice de la corona. Estas características son constantes en todos los especímenes examinados, por lo que se piensa que corresponden a una especie no descrita. Los folículos unidos, que aquí se describen por primera vez para el género, confirman su relacionan con Thenardia HBK. lal como lo habia expresado Williams (2002a).
Thoreauea guerrerensis N. Diego \& Lozada-Pérez. sp. nov. TIPO: México. Guerrero: Mun. General Heliodoro Castillo, km 10, amino de Puerto El Jilguero a Puerto del Gallo, 27 Abr. 1983, F. G. Lorea 2401 (holotipo, FCVE; isotipos, IEB. MEXU. MO. XAL). Figura 1 .

Haec species Thoreanea paneroi affinis, sed corona corollina vix lo-lobata apice et staminibus coronam aequantibus differt.

Lianas con látex acuoso; tallos cilíndricos de 3$3.5 \mathrm{~mm}$ diám.. glabros. Hojas opuestas a subopuestas. pecioladas; láminas $10-14 \times 2.5-4.5$ cm, elípticas a oblongas, ápice acuminado. margen entero, base obtusa, venación pimnada, con 7 a 15 pares de venas secundarias laterales, haz verde oscuro, lustrosa. glabra, sin coléteres en la base de la lámina, envés verde pálido, glabro; pecíolos 2-2.6 cm de largo, con tricomas multicelulares en su lado adaxial: con 2 coléteres en la hase. $0.8-1.3 \mathrm{~mm}$ de largo. lanceolados y café oscuro cuando secos, fusionados intrapeciolarmente y unidos a un reborde interpeciolar para formar un anillo alrededor del nudo. Flores 25 a 30 , dispuestas en una cima subumbelada, tricótoma. axilar, 3.5-1.5 ( $\mathrm{m}$ de largo, más corta que las hojas: pedúnculos $1.5-3.5 \mathrm{~cm}$ de largo, glabros; brácteas I$2 \times 0.5 \mathrm{~mm}$, oblongas a estrechamente oblongas, con 2 coléteres laterales en la base, glabras; pedicelos 0.9-1 cm de largo, glabros. Lóbulos del cáliz divididos casi hasta la base, subiguales, $1-1.5 \times$ $\mathrm{l}-1.2 \mathrm{~mm}$, triangulares, erectos, glabros, con un coléter opuesto a cada lóbulo en su lado adaxial, $0.5-0.7 \mathrm{~mm}$ de largo, ovado, ápice truncado y denticulado. Corola pentámera, raramente tetrámera, blanca, urceolada; tubo $3.5-4.5 \mathrm{~mm}$ de largo, ca $3.5 \mathrm{~mm}$ de ancho en la base, base ensanchada, glabra, lóbulos subiguales, $2.5-3.5 \times 2.5-3 \mathrm{~mm}$, ovados a ampliamente ovados, ápice obluso, redondeado a truncado, ciliolado, márgenes ligeramente asimétricos, garganta con una corona anular carnosa, 1.3$1.5 \mathrm{~mm}$ de largo, 10-lobulada en el ápice, los lóbulos $0.3-0.4 \times 0.5-0.7 \mathrm{~mm}$, ápice redondeado a truncado. Estambres 5, raramente 4, 4.5-5 $\mathrm{mm}$ de largo, lan largo como la corona; filamentos ca. $3 \mathrm{~mm}$ de largo. unidos cerca de la base de la corola, flexionados hacia

Novon 16: 332-335. Publishld on 7 November 2006. 


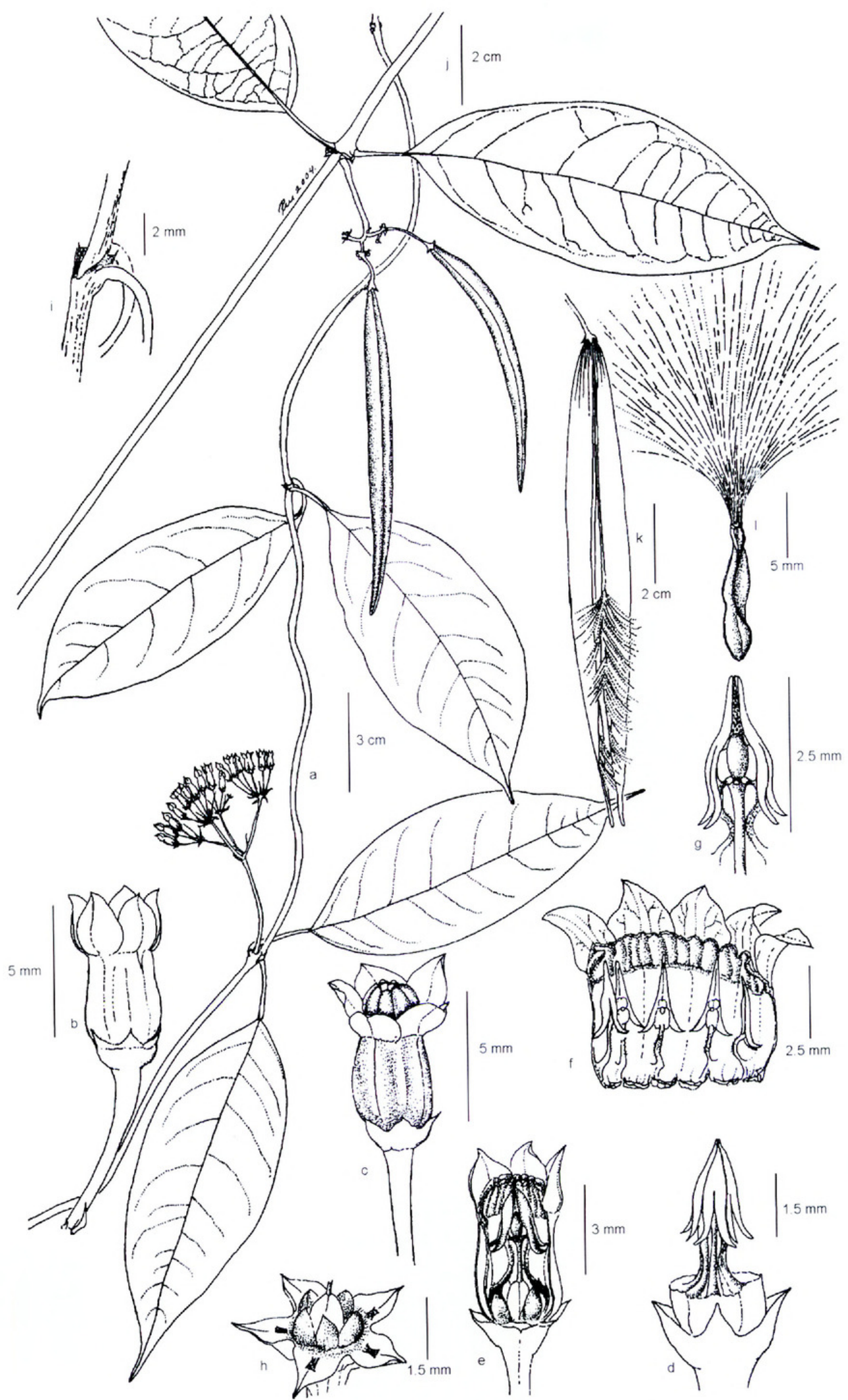

Figura 1. Thoreauea guerrerensis N. Diego \& Lozada-Pérez. —a. Rama con hojas e inflorescencia. — b. Vista externa de la corola con la corona en la garganta. — d. Flor con la corola removida. — e. Flor con la corola parcialmente corola

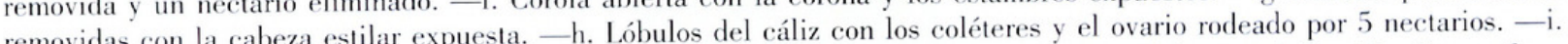
Pecíolos con coléteres unidos en la axila. — j. Rama con frutos. — k. Fruto parcialmente abierto. —l. Semilla. Drawn from Diego \& M. Castro 9247 (FCME). 
adentro, formando un tubo alrededor del estilo y engrosados en el ápice, blanco pubescentes lateral y ventralmente, el dorso glabro; anteras amarillas, 2.7$3 \mathrm{~mm}$ de largo, base sagitada con los lóbulos flexionados hacia fuera; pistilo $3.5-4 \mathrm{~mm}$ de largo; ovario súpero, formado por 2 carpelos fusionados, $0.8-$ $1 \mathrm{~mm}$ de largo, ovoide, glabro, rodeado por 5 nectarios erectos, ca. $0.8-1 \mathrm{~mm}$ de largo, tan largos o escasamente más cortos que el ovario, unidos en la base ca. $0.5 \mathrm{~mm}$; estilo $2.8-3 \mathrm{~mm}$ de largo, glabro: cabeza estilar $0.7-1 \mathrm{~mm}$ de largo, elipsoide (material fresco), ápice bilobado, aglutinado a las anteras, con un collar membranáceo en la base, aglutinado al ápice de los filamentos. Folículos 2, fusionados, 12-16 $\times$ $0.5-0.7 \mathrm{~cm}$, angostamente aplanado elipsoides, $\mathrm{g} \mathrm{l}_{\mathrm{a}-}$ hros, dehiscentes longitudinalmente. Semillas pardas, $1.5-1.7 \mathrm{~cm}$ de largo, lado proximal cóncavo, el distal convexo y a veces aquillado engrosado, margen alado y entero, lado distal verrucoso hacia el centro, coma blanco amarillento, 3-4 cm de largo.

Distribución y fenologia. Thoreauea guerrerensis se conoce de la Sierra de Guerrero, México en los límites de los municipios de Atoyac de Alvarez y General Heliodoro Castillo. Tiene como hábitat los lugares sombreados del bosque de Pinus I.., Quercus l. y Abies Miller y el bosque mesófilo de montaña que se encuentran entre 2400 y $26.50 \mathrm{~m}$ de altitud. También han sido recolectados especímenes estériles a $1800 \mathrm{~m}$ de altitud. Florece de abril a octubre y fructifica de junio a diciembre.

Epíteto especifico. El epíteto específico honra al estado de Guerrero, donde se han recolectado todos los especímenes citados.

Thoreauea guerrerensis comparte con T. paneroi la mayoría de los caracteres vegetativos, particularmente aquellos relacionados con el tallo y las hojas. Williams (2002a) describe para T. paneroi la presencia de látex lechoso, sin embargo en especímenes colectados por nosotros en abril de 2006 en la misma localidad lipo de esa especie encontramos la presencia de látex acuoso, misma condición que presenta la especie que aquí se describe; carácter que no es mencionado en la redescripción que del género realiza Morales (2005), o de T. aberrans J. F. Morales. que él mismo describe. En T. paneroi se menciona la presencia de coléteres y una bráctea relacionados al pecíolo, sin embargo, nuestras observaciones establecieron que los coleléres forman un continuo intrapeciolar, que tal vez correspondería a lo que Williams (2002a) describe como brácteas. Tales caracteres lambién fueron observados en un espécimen (J. I. Calzada 19725, depositado en MEXU, no revisado por Williams) colectado cerca de la localidad tipo de $T$. paneroi, por lo que suponemos que ambas especies comparten dicho carácter. En ambas especies los pecíolos son pubescentes adaxialmente. Los caracteres vegetativos de la inflorescencia también son muy similares. Las diferencias fundamentales entre ambas especies se encuentran en los caracteres florales. En T. guerrerensis el tubo de la corola es de $3.5-4.5 \mathrm{~mm}$ de largo y en T. paneroi es de $5-6 \mathrm{~mm}$ de largo. En $T$. guerrerensis la corona es ligeramente 10-lobulada en el ápice, cada lóbulo de $0.3-0.4 \mathrm{~mm}$ de largo. a diferencia de $T$. paneroi que presenta una corona profundamente 5-lobulada, con los lóbulos de 1.4 $1.6 \mathrm{~mm}$ de largo; la existencia de 5 lóbulos fue diagnosticado posteriormente por Morales (2005) al examinar flores de la colección tipo y confirmado por nosotros en especímenes recolectados en la localidad lipo de dicha especie. En T. guerrerensis los filamentos son ligeramente más largos y son del mismo grosor en toda su longitud, no así en $T$. paneroi que posee filamentos más cortos y gradualmente engrosados hacia la base. En ambas especies los filamentos son pubescentes adaxialmente y glabros abaxialmente, pero en $T$. guerrerensis el indumento es de color blanco y menos denso y en $T$. paneroi el indumento es pardo y más denso. En la descripción original de $T$. paneroi se había considerado que los nectarios que rodean al ovario se encontraban libres, sin embargo en el material recolectado por nosotros en la localidad tipo los nectarios se encuentran unidos, por lo que suponemos que tal carácter es compartido por ambas especies, sin embargo una conclusión definitiva al respecto se alcanzara cuando sean recolectados más especímenes, ya que existe el ejemplo de Echites turrigera Woodson, especie que puede tener nectarios libres o unidos (Williams, 2002b). Finalmente en ambas especies el ápice de la cabeza estilar es bilobado, carácter que no ha sido descrito para el género (Williams, 2002a; Morales, 2005).

Por lo que respecta a Thoreauea aberrans, esta especie es fácilmente contrastable con T. guerrerensis ya que presenta una corola campanulada, con el tubo de $2.5-3 \mathrm{~mm}$ de largo y una corona anular inconspicuamente lobulada.

Paratipos. MEXICO. Guerrero: Mun. Heliodoro Castillo. Cañada de Las Margaritas, N. Diego, E. Acosta \& G. Fernández 8781 (FCME, IEB, MEXU): Cañada de Las Margaritas, N. Diego, M. Castro \& G. Fernández 9037 (FCME, IEB, MEXU): Cañada de Las Margaritas. N. Diego \& V. Castro 9247 (FCME: IEB, MEXU): Cañada de Las Margaritas, N. Diego \& $R$. de Santiago 9320 (FCME, IEB. MEXU): Entre el Jilguero y Las Margaritas, E. León. L. Lozada \& J. Rojas 223 (FCME, IEB. MEXU).

Agradecimientos. Los autores dan las gracias a Martha Martínez por la diagnosis en latín y a Ramiro Cruz por la elaboración del dibujo. Este trabajo es resultado del proyecto "Estudio de tres localidades de 
bosque mesófilo en el estado de Guerrero", apoyado por el Consejo Nacional de Ciencia y Tecnología (clave 3164P-N9608).

\section{Literatura Citada}

Morales, J. F. 2005. Estudios en las Apocynaceae Neotropicales XV: Sinopsis del género Thoreauea (Apocynoi- deae, Echiteae), con una nueva especie de Veracruz, México. Brittonia 57(3): 258-263.

Williams, J. K. 2002a. Thoreauea (Apocynaceae: Apocynoideae), a new genus from Oaxaca, Mexico. Lundellia 5: $47-58$.

- 2002b. A further evaluation of Echites sect. Yucatanense (Apocynaceae) with additional notes on the genus. Brittonia 54(4): 310-317. 


\section{$2 \mathrm{BHL}$ Biodiversity Heritage Library}

Diego Pérez, N and Lozada-Pérez, Lucio. 2006. "Thoreauea guerrerensis (Apocynaceae, Apocynoideae), una nueva especie de Guerrero, México." Novon a journal of botanical nomenclature from the Missouri Botanical Garden $16,332-335$.

View This Item Online: https://www.biodiversitylibrary.org/item/41804

Permalink: https://www.biodiversitylibrary.org/partpdf/37312

\section{Holding Institution}

Missouri Botanical Garden, Peter H. Raven Library

\section{Sponsored by}

Missouri Botanical Garden

\section{Copyright \& Reuse}

Copyright Status: In copyright. Digitized with the permission of the rights holder.

License: http://creativecommons.org/licenses/by-nc-sa/3.0/

Rights: https://biodiversitylibrary.org/permissions

This document was created from content at the Biodiversity Heritage Library, the world's largest open access digital library for biodiversity literature and archives. Visit BHL at https://www.biodiversitylibrary.org. 